\title{
Seafarer Cross-Generational Competence Skills
}

\section{Olena Tyron}

It was mentioned that the ability to establish a positive relationship between the members of international crews is an urgent issue. This ability influences not only the safety of navigation, but the mental health of seafarers as well. Foreign language competence is essential for the resolution of this problem. Successful everyday communication of seafarers depends on a number of factors: the awareness of cross-cultural, religious and cross-generational differences will help establish a friendly communication onboard a ship with an international crew. This paper presents a study on cross-generational communication of future seafarers. Our study empirically proved that the ability of mutual communication between different age groups facilitates the establishment of friendly relationships onboard a ship. A psychological insight into the peculiarities of different generations helped us see the process of communication of seafarers in a new light. We outlined the main values of different generations, allowing the students to learn the preferred topics of everyday communication. In our opinion, the results of this study may be used by lecturers of maritime educational establishments in the scope of the course Psychology and English language.

\section{KEY WORDS}

$\sim$ Cross-generational communication

$\sim$ Cross-cultural values

$\sim$ Age perception

$\sim$ Everyday communication

Kyiv State Maritime Academy, Kyiv, Ukraine

E-mail: ollena22@hotmail.com

\section{INTRODUCTION}

The issue of foreign language competence of seafarers is widely studied nowadays. In our earlier research we defined the factors required for the development of foreign language competence in future seafarers (Tyron, 2013). One of the determinants of successful daily communication onboard a ship with an international crew is the skill of communication with sailors of different age groups.

Let us analyze the term competence. Competence is generally defined as skills, qualifications and knowledge giving a person the ability to work as a part of a professional team or, when it comes to maritime activities, a crew. According to a study conducted by the Seafarer's International Research Centre (SIRC) in the late 1990's, the lack of crew competence is a growing problem. Proficiency in English is one clear example. The Seafarer's International Research Centre defines crew competence as "a uniform standard of the provision of high quality training and educational opportunities at least as important as professional training". It emphasizes the importance of the so called "silent knowledge comprising unwritten roles and attitudes of the seafaring culture. Further, competence is a mixture of technical and social skills and a place where terminology and vocabulary are taken for granted" (Lane 1999). In conclusion, one could say that competence is a sum of education and experience. According to Ding \& Liang (2005), competence includes knowledge, skills and understanding in terms of communication, with emphasis on issues such as fluency in English. Competence also includes physical and psychological attitudes, including attitudes towards maritime safety and health standards (Berg et al., 2013).

The theoretical bases of research on cross-generational international communication in an international crew were:

- Ukrainian theory of generations ( L.S Vygotsky);

- Western scholars ( Giambattista Vico and Jean Condorcet);

- American theory of generations (Neil Howe and William Straus). 
- the theory of communicative accommodation and the model of stereotypes implemented in cross-generational communication (Williams and Giles, 1996; Giles et al., 2001; Williams \& Garrett 2002).

\section{DESCRIPTION OF THE RESEARCH}

1. Program and basic methods of empirical research.

The goal of the research was to analyze the influence of cross-generational communication skills on the establishment of friendly relationships onboard a ship, especially in international crews. In order to fulfil the tasks, achieve the goals and confirm our hypothesis, a number of methods were used:

- theoretical - the analysis of psychopedagogic, psycholinguistic literature, reports and other information resources of offshore international organizations in order to determine the theoretical and methodological principles of research, open its conceptual-categorical apparatus, clarify the status of the problem and generalize and systematize major theoretical positions to determine the psychological and pedagogical factors relevant for the development of foreign language communicative competence of future seafarers;

- empirical methods - questionnaires, interviews, teacher observations, testing and expert evaluation to determine the level of development of foreign language communicative competence of future sailors, psycho-pedagogical experiment to test the hypothesis of the research, mathematical statistics to determine the statistical significance of obtained results.

2. Conditions and purpose of research.

Experimental research work was carried out at the Kyiv State Maritime Academy with full-time and part-time students of the $2^{\text {nd }}, 3^{\text {rd }}$ and 4 year of the Faculty of Navigation, specializing in "ship navigation and control" and "operation of ship power plants". The practical implementation of the tasks was carried out in two stages: forming and stating experiments. The objective of the first stage was to test the hypothesis that cross-generational skills are relevant for the establishment of successful communication onboard a ship with an international crew. 60 students of the Navigation and Engineering Department were interviewed. The first test was "The test of defining the need in communication by Ryakhovskyi", which is widely used by Ukrainian psychologists. The results were:

- $60 \%$ of the respondents scored $14-18$ points. That means normal sociability. They are curious, willing to listen to their interlocutor, patient in communication, defend their point of view. They accept contact with strangers but do not like noisy groups of people.

$30 \%$ of the respondents scored 9-13 points. They are very sociable, fond of expressing their own ideas on different topics.
They are keen on meeting new people, quick tempered, show lack of patience.

- $10 \%$ are overcommunicative. They take up any cause, although they do not always bring it to completion.

So, none of the students surveyed had any problems with communication in their native language, but when it came to communication in English onboard a ship, they mentioned difficulties, mostly psychological in character (Tyron, 2013). We paid special attention to the students' answers to the following test question: "Do you think that people of different generations have difficulties understanding each other?" In spite of the results of the test which proved high communicative abilities of the students in general, $85 \%$ of respondents answered "yes" and $15 \%$ - answered "no". This goes to show that the development of ability to communicate with people of different age groups must be made one of the goals of training of future seafarers. For further research of this subject matter we designed a test for the students of the academy who took part in the experiment. Inter alia, it contains the following questions:

"What was the age composition of the crew you had your shipboard training with?"

- $\quad$ "Did you have any problems in communication with older people?"

- "Can you initiate a conversation with an older worker?"

- "Do you prefer talking to younger workers?"

In this test we used the term "older workers" for persons aged 41-50 and "younger workers" for persons aged 31-40.

Although this kind of testing is still in progress, we worked under the assumption that most students: 1. work in different age groups; 2 . have difficulty finding common topics with older workers; 3. prefer talking to younger workers. In our opinion, when preparing students for communication onboard a ship we have to consider the age structure of its crew. It would be beneficial to introduce elements raising cross-generational awareness prior to the students' first shipboard training. It would certainly have a positive impact on the psychological climate among seafarers, especially in international crews.

\section{STATISTICAL ANALYSIS}

\subsection{Statistical analysis of the composition of international crews}

Let us turn to statistics published in a scientific research conducted by international research centre of seafarer authors Ellis $\mathrm{H}$ and $\mathrm{H}$. Sampson (Seafarers International Research Centre (SIRC) (Ellis and Sampson, 2008). 
Table 1.

Age of seafarers.

\begin{tabular}{|lll}
\hline Age & Percentage & $\begin{array}{l}\text { Cumulative } \\
\text { percentage }\end{array}$ \\
\hline 20 or younger & $1.2 \%$ & $1.2 \%$ \\
\hline $21-30$ & $26.1 \%$ & $27.4 \%$ \\
\hline $31-40$ & $30.5 \%$ & $57.9 \%$ \\
\hline $41-50$ & $27.6 \%$ & $85.5 \%$ \\
\hline $51-60$ & $13.1 \%$ & $98.6 \%$ \\
\hline 61 and older & $1.4 \%$ & $100.0 \%$ \\
\hline Total & $100.0 \%$ & \\
\hline
\end{tabular}

As we can see, three age groups predominate on vessels. Since students have a long shipboard practice after their third year of study, they fall under the group of 21-30 year olds, accounting for $26.1 \%$ of the crew and ranking third in the statistics. Therefore, we can draw the following conclusions:

- third and fourth year maritime academy students will work in their own age group during their shipboard training - the third ranking group.

- $\quad$ students must possess the skill of successful communication with 31-40 year olds - the most numerous group.

- $\quad$ students must be able to establish communication with seafarers aged 41-50 - the second ranking group.

Table 2.

Top 10 Nationalities of Junior Officers.

\begin{tabular}{lll} 
Rank Order & Nationality & Percent \\
\hline 1 & Philippines & $24.2 \%$ \\
\hline 2 & Russian & $9.4 \%$ \\
\hline 3 & India & $7.8 \%$ \\
\hline 4 & Ukraine & $7.8 \%$ \\
\hline 5 & China & $6.8 \%$ \\
\hline 7 & Greece & $3.5 \%$ \\
\hline 8 & Poland & $3.2 \%$ \\
\hline 10 & Korea, South & $3.1 \%$ \\
\hline Other & Indonesia & $2.9 \%$ \\
\hline Total & Romania & $2.4 \%$ \\
\hline
\end{tabular}

Separately, we considered the category of students who have shipboard training after their second year of study. They usually belong to the first, least numerous age group of 20 or younger. This is due to the unavailability of work for them on non-training ships. International crewing companies have high requirements for cadet training and knowledge of English language, and besides, students are not yet ready to go to long voyages. But nevertheless, a small percentage of students from this age group is present onboard ships. As you see, the task of development of cross-generational communication skills is urgent.

Being trained as cadets, the students will contact Junior Officers. Having reviewed the data from Table 2, we came to the conclusion that the students' potential interlocutors are Filipinos, Russians, Indians and Chinese, not excluding other nationalities.

Some students will train for first and second rank sailors. Let us turn to the ethnic composition of the ratings. As you see from Table 3, in this case, their potential interlocutors are Russians, Indians, Filipinos and Chinese, not excluding other nationalities.

Table 3.

Top 10 Nationalities of Ratings.

\begin{tabular}{lll}
\hline Rank Order & Nationality & Percent \\
\hline 1 & Philippines & $36.7 \%$ \\
\hline 2 & China & $6.3 \%$ \\
\hline 3 & Ukraine & $5.9 \%$ \\
\hline 4 & Russian & $5.5 \%$ \\
\hline 5 & India & $5.2 \%$ \\
\hline 6 & Turkey & $4.4 \%$ \\
\hline 7 & Indonesia & $4.1 \%$ \\
\hline 8 & Poland & $2.7 \%$ \\
\hline 9 & Myanmar I & $2.6 \%$ \\
\hline 10 & Bulgaria & $2.1 \%$ \\
\hline Other & (n=106 ) & $24.5 \%$ \\
\hline Total & & $100.0 \%$ \\
\hline
\end{tabular}

Communication between the ranks is organized according to seniority rules. But in addition to performing functional duties onboard a ship and on shore, entertainment events are also known to be held at sea, at which cadets will have an opportunity to socialize with senior officers in an informal setting.

Thus, as seen from Table 4, Filipinos represent about $11 \%$ of the senior officers, Russians $10 \%$, Ukrainians $7.4 \%$, with Greeks and Indians having almost the same rating. Therefore, students will have the opportunity to demonstrate their communication skills to persons of other ranks, with their main potential 
education. Gen X still reads a lot to get ahead professionally and is grateful when employers allow them to share their knowledge. One of the main challenges of Generation $X$ is fatigue. It is this generation that had to learn to adjust to external circumstances to be successful in the new environment. Many of them received second education, changed their scope of work. Many believe that Gen $X$ is plagued by lack of motivation. After all, Generation $X$ had to raise and nurture Gen $Y$, conveying it its experience and knowledge. Unlike the $X^{\prime}$ 's, the Millenniums (Y) are much more ambitious, including in terms of remuneration. "Members of this generation will insist on higher wages regardless of their knowledge and skills. Moreover, they believe that they are underpaid. They are guided by the logic of "required fees" and "unjust reward"'.' No matter how much I take - I have to, because it is important that I do" (Новиков, 2008). But we have much to be grateful for to this generation.

We have identified three age groups that are of interest for the further development of our research. However, the above division is inadequate. According to our statistical analysis, Generation X, born 1965-1982, should be divided into the following ages groups: 31-40, representing $30.5 \%$ and 41-50, representing $26.7 \%$. The characteristics of these age groups onboard a ship will differ due to:

- $\quad$ the small number of crew members (10-20 people):

- living in closed space and

- different life experience.

\subsection{Nationality-dependent perception of age}

We should check whether different nationalities perceive age differently.

As previously mentioned, the majority of interlocutors onboard an international ship are sailors from Eastern countries. The analysis of research into age perception of Eastern and Western countries is essential. Research on the influence of cultural values and beliefs on attitudes towards aging has been dominated by comparisons of Eastern/Asian and Western cultures (see Giles et al. 2003 for a review) (Lockenhoff et al., 2009; Романов, 2009).This body of work was inspired by the idea that Asian societies are influenced by Confucian values of filial piety and the practice of ancestor worship which are thought to promote positive attitudes towards aging and high esteem for the elders (e.g., Davis, 1983; Sher, 1984; Ho, 1994; see Sung 2001 for a review). Western societies, in contrast, were thought to be youth-oriented and have a more negative attitude towards aging and the elderly (e.g., Palmore, 1975). Empirical evidence for the proposed East-West differences is scarce. Although some studies have found support for the hypothesis that attitudes towards aging are more positive in Asian than in Western cultures (e.g., Levy and Langer, 1994; Tan, Zhang, and Fan, 2004), others report effects in the opposite direction (e.g., Giles et al., 2000; Zhou, 2007; Harwood et al., 2001; Sharps, Price-Sharps and Hanson, 1998), or fail to find any marked cultural differences (e.g., Boduroglu, Yoon, Luo, and Park, 2006; Ryan, Jin, Anas, and Luh,2004; Chappel, 2003; McCann, Cargile, Giles, and Bui, 2004) (Lockenhoff et al., 2009).

After studying different research, while we arrived at the conclusion that differences in the perception of age between nationalities that may be present onboard a ship are not profound, we still recognize that since Eastern countries have a tradition of living in extended families, their inhabitants are more skilful in communication with older workers. Since in Western countries young people often start living separately, they are more used to communicating with persons from their own age group. To integrate the findings of the present study with the previous literature, we also examined gross-level "Eastern" versus "Western" contrasts. To group the cultures in our sample according to broad Asian/Eastern versus Western categories, we drew on the United Nations geographical regions (United Nations Statistics Division, 2008). According to these guidelines, we classified the following countries as Eastern/Asian: Hong Kong, India, Iran, Japan, Mainland China, Malaysia, and South Korea. The Western group was comprised of European cultures (Croatia, Czech Republic, Estonia, France, Great Britain, Poland, Portugal, the Russian Federation, Serbia, Slovakia, and Switzerland) and the U.S. (Lockenhoff et al., 2009).

\section{CONCLUSION}

Bearing in mind the issue of age differences before coming to work onboard a ship with an international crew, future seafarers should acquire a good level of adequate cross-generational and cross-age communication skills. It means:

- they should be aware of the topics of interest of different age groups;

- they should be aware of cultural differences between Eastern and Western countries pertaining to age stereotypes;

- they should be able to accommodate to different cultural attitudes to cross-generational communication;

- they should be aware of their own stereotypes pertaining to cross-generational communication.

We strongly recommend the introduction of ideas of cross-generational awareness into the curriculums of maritime institutions as a part of a cultural awareness course. 


\section{REFERENCES}

Berg, N., Storgård, J. and Lappalainen, J., (2013), The Impact of Ship Crews on Maritime Safety, Publications of the centre for maritime studies, Turku: University of Turku, pp. 45, available at: http://mkkdok.utu.fi/pub/A64-impact\%20of\%20 crews\%20on\%20safety.pdf, [accessed 30 March 2014.].

Ellis, N. and Sampson, H., (2008), The Global Labour Market for Seafarers: Working Aboard Merchant Cargo Ships 2003, Cardiff: The Seafarers International Research Centre, Cardiff University, available at:http://www.sirc.cf.ac.uk/uploads/ publications/GLM\%20for\%20Seafarers.pdf, [accessed 30 March 2014.].

Lockenhoff, C., De Fruyt, F., Terracciano, A., McCrae, R., De Bolle, M., Costa, P., AguilarVafaie, M., Ahn, C.-K., Ahn, H.-N., Alcalay, L., Allik, J., Avdeyeva, T., Barbaranelli, C., BenetMartinez, V., Blatný, M., Bratko, D., Cain, T., Crawford, J., Lima, M., Ficková, E., Gheorghiu, M., Halberstadt, J., Hřebíčková, M., Jussim, L., Klinkosz, W., Knežević, G., Leibovich de Figueroa, N., Martin, T., Marušić, I., Mastor, K. A., Miramontez, D., Nakazato, K., Nansubuga, F., Pramila, V. S., Realo, A., Rolland, J.-P., Rossier, J., Schmidt, V., Sekowski, A., Shakespeare-Finch, J. E., Shimonaka, Y., Simonetti, F., Siuta, J., Smith, P., Szmigielska, B., Wang, L., Yamaguchi, M. and Yik, M., (2009), Perceptions of aging across 26 cultures and their culture-level associates, Psychology and Aging, 24(4), pp. 941-954., http://dx.doi.org/10.1037/a0016901

Новиков, С. В., (2008), Theory of Generations, Теория поколений (in Russian), available at: http://www.svblog.ru/consult/KK-3/5/, [accessed 30 March 2014.]

Романов, А., (2009), Intergenerational communication, Межпоколенческая коммуникация (in Russian), Moscow: Knizhnyy dom "LIBROKOM".

Tyron, O. M., (2013), Determinants of Successful Everyday Communication of Sailors in International Crews, Journal of Educational and Social Research, 3(3), pp. 209-211., http://dx.doi.org/10.5901/jesr.2013.v3n3p209 